\title{
General Method for the Isolation of Conditional Lethal Mutants in Any Required Region of the Virus Genome: Its Application to the 'Semi-essential' Region of Phage Mu
}

\author{
By L. PAOLOZZI* AND P. GHELARDINI \\ Centro Acidi Nucleici del CNR, Istituto di Fisiologia Generale, Universitá di Roma \\ 'La Sapienza', 00100 Rome, Italy
}

(Received 8 July 1985; revised 9 September 1985)

\begin{abstract}
A general method is presented that enables viral mutants to be isolated in any required region of their genome. An application of the method is reported relating to the isolation of conditional lethal mutants in the 'semi-essential' region of phage $\mathrm{Mu}$. Some properties are described of one mutant found in this way, Mucts ${ }_{62}$ SEEam8 Apl, which is typical of a class of mutants that were isolated.
\end{abstract}

\section{INTRODUCTION}

It is of ten required to isolate viral mutants with mutations in a particular genome region. Here we describe a method which allows this to be done. The only requirement is that the desired region can be cloned into a plasmid and that the viral genes it contains are expressed in cells that are hosts for the growth of the virus. The method consists of mutagenizing a stock of the virus and then infecting host cells that contain the relevant plasmid. Only mutations in those viral genes expressed by the viral fragment on the plasmid will be complemented - other viral mutations will not, and hence upon infection the only mutants affected in essential genes that will be able to multiply will be those with mutations in the required region. Subsequently, these mutants can be distinguished from the wild-type virus by testing the released virus on indicator strains with and without the particular plasmid.

We describe the application of this method to the selection of phage mutants in the 'semiessential' region of coliphage Mu (for a review see Toussaint \& Resibois, 1983). This region lies between 5 and $10 \mathrm{~kb}$ at the left or $c$ end of the genome (Fig. 1) and plays an intriguing role in the $\mathrm{Mu}$ life cycle. The 'semi-essential' genes are read from the same early transcript as the early genes $A$ and $B$, but are not absolutely necessary for Mu transposition, even though they modify the synthesis of Mu DNA in different ways (Goosen et al., 1982; Waggoner et al., 1981). Little is known about the genes of this region. Previously only one report has been published of conditional lethal mutants mapping in this region. This refers to a class of temperature-sensitive mutants in the so-called lig gene, whose product is expressed constitutively and is able to complement the lig gene of Escherichia coli K12 (Paolozzi et al., 1980). The Mu lig protein is apparently involved at some stage in the integration step which precedes $\mathrm{Mu}$ replication.

\section{METHODS}

Bacteria and phages. These are listed in Table 1

Mutant isolation procedure. A $50 \mathrm{ml}$ Luria broth (LB) culture of an E. coli K12 strain that is (a) Sup ${ }^{+}$not permissive for amber mutations, (b) lysogenic for Mucts ${ }_{62} \mathrm{Apl}$, and (c) carries the plasmid pKN165 (see Fig. 1), was grown at $30^{\circ} \mathrm{C}$ to a concentration of $2 \times 10^{8} \mathrm{ml}^{-1}$ and then treated with $N$-methyl- $N^{\prime}$-nitro- $N$ nitrosoguanidine (Sigma) as described previously (Paolozzi et al., 1980). The culture was then diluted 100-fold into LB and divided into five parts; these five cultures were allowed to grow at $30^{\circ} \mathrm{C}$ to stationary phase. Each culture was then diluted and plated onto L-plates at $30^{\circ} \mathrm{C}$ to give approximately 100 colonies per plate. The colonies were 

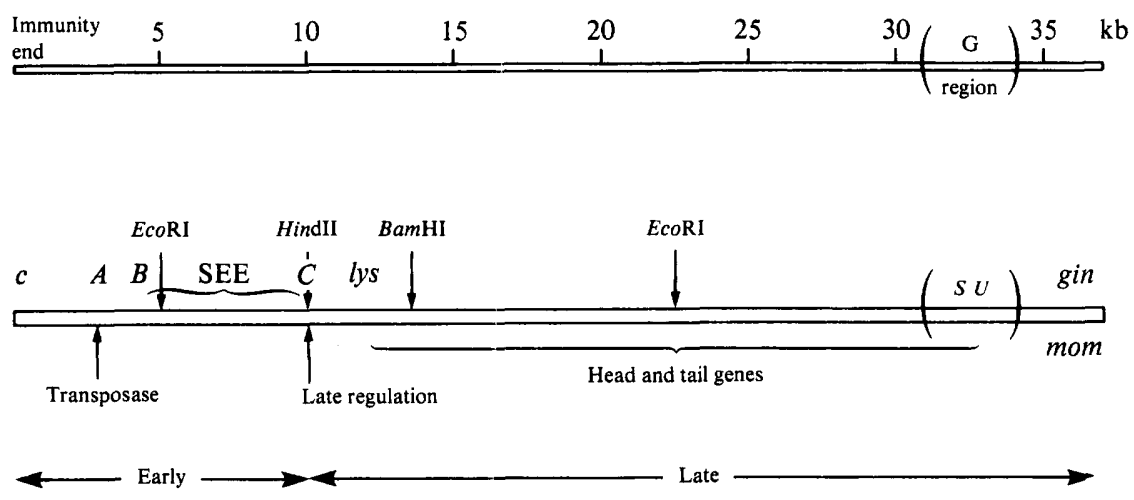

pKN 165

pKN50

Fig. 1. Simplified map of the Mu genome. The 'semi-essential' early region (SEE) lies between genes $B$ and $C$. The pKN plasmids (which were gifts of W. Schumann) are derivatives of pBR325 (Bolivar et al., 1977). pK N50 contains the Mu fragment lying between the left-end EcoRI and BamHI sites, indicated in the figure (Schumann et al., 1980). pKN165 (constructed by T. Baron) was derived from pK N50 by deleting the internal HindII fragment. pKN165 does not complement mutations in either the $C$ or lys genes of $\mathrm{Mu}$ (contrary to pKN50), but it does complement the Mu ligts2 mutation.

Table 1. Bacteria and phages
E. coli strain
Source or reference

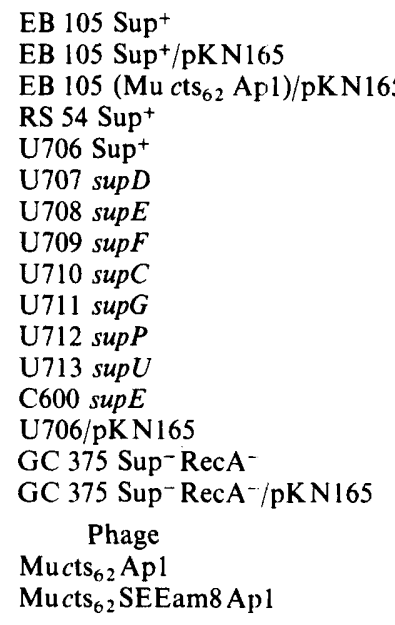

\author{
Schumann et al. (1980) \\ Provided by W. Schumann \\ This work

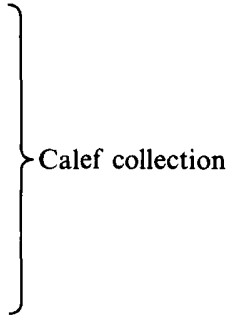 \\ This work \\ Provided by J. C. Liebart \\ This work \\ Leach \& Symonds (1979) \\ This work
}

replica-plated in duplicate: (i) to preserve the colonies, onto L-plates incubated at $30^{\circ} \mathrm{C}$; (ii) to test for the phage produced by the lysogenic colonies, on to L-plates incubated at $42^{\circ} \mathrm{C}$ and seeded with mixed indicator containing $\mathrm{Sup}^{+}$and $\mathrm{Sup}^{+} / \mathrm{pKN} 165$ bacteria, in a ratio of $1: 2$. Any Mu mutants in the region covered by pKN 165 could easily be identified as they give turbid plaques on the mixed indicator. Colonies from the master plate corresponding to the turbid plaques were resuspended in $2 \mathrm{ml} \mathrm{LB}$ and grown to $5 \times 10^{7} \mathrm{ml}^{-1}$ at $30^{\circ} \mathrm{C}$, and then the cultures were shifted to $42{ }^{\circ} \mathrm{C}$ to obtain phage lysates. These lysates were retested by spotting directly onto plates seeded with either Sup ${ }^{+}$or $\mathrm{Sup}^{+} / \mathrm{pKN} 165$ bacteria, and a further distinction between amber and non-amber mutants was made by spotting on Sup $^{-}$and Sup ${ }^{-} / \mathrm{pKN} 165$ bacteria. 
Table 2. E.o.p. and burst size of Mucts ${ }_{62}$ SEEam8 Ap1 on strains with different amber or ochre suppressors

The e.o.p. was tested by plating $0 \cdot 1 \mathrm{ml}$ from a dilution series of $\mathrm{Mucts}{ }_{62} \mathrm{SEEam} 8 \mathrm{Apl}$ onto plates seeded with different indicators. The best of the suppressors is $\sup F$, on the basis of both the number of plaques observed and the sizes of the plaques, which were comparable to those observed on U706/pKN165. To measure burst size, bacteria $\left(1 \times 10^{8} \mathrm{ml}^{-1}\right)$ were infected at an m.o.i. of $0 \cdot 25$. After $13 \mathrm{~min}$ at $37^{\circ} \mathrm{C}$, nonadsorbed phage were eliminated by two successive centrifugations and the pellet resuspended at $10^{8}$ cells $\mathrm{ml}^{-1}$ and treated for 2 min with anti-Mu serum (fractional rate of inactivation, $K=300$ ). The culture was then diluted $10^{4}$-fold into LB at $37^{\circ} \mathrm{C}$. A sample was tested immediately on strain U706/pKN 165 to determine the number of infective centres $(A)$. The rest of the culture was aerated at $37^{\circ} \mathrm{C}$ for a further $60 \mathrm{~min}$ and then lysed with $\mathrm{CHCl}_{3}$. The lysate was plated on L-plates seeded with U 706/pKN $165(B)$. The burst size is given by the ratio $B / A$. The results are means of three independent experiments. NT, Not tested.

$\begin{array}{lcc}\begin{array}{c}\text { E. coli } \\ \text { strain }\end{array} & \text { E.o.p. } & \begin{array}{c}\text { Burst } \\ \text { size }\end{array} \\ \text { U706 Sup }{ }^{+} & 5 \times 10^{-5} & 0.8 \\ \text { U706/pKN } 165 & 1 & 200 \\ \text { U707 supD } & 8 \times 10^{-1} & \text { NT } \\ \text { U708 supE } & 7 \times 10^{-1} & \text { NT } \\ \text { U709 supF } & 1 & 23 \\ \text { U710 supC } & <10^{-4} & <1 \\ \text { U711 supG } & <10^{-3} & <1 \\ \text { U712 supP } & 7 \times 10^{-1} & \text { NT } \\ \text { U713 supU } & <10^{-3} & <1\end{array}$

\section{RESULTS AND DISCUSSION}

Results from the isolation procedure described showed that approximately $0.5 \%$ of the total colonies examined after mutagenesis yielded mutants that were complemented by pKN 165 . About $20 \%$ of these mutants were stringent, in that they only produced plaques on bacteria carrying plasmid pKN 165 ; the other $80 \%$ were leaky and made tiny plaques on the plasmid-free indicator. Among the 64 mutants isolated in this series, 50 were amber mutants; some preliminary results concerning these are reported below.

In order to eliminate any effect of recombination between the Mu lysogens and the $\mathrm{Mu}$ region of $\mathrm{pKN} 165$, the amber mutants were first repurified by growing lysates in a $\mathrm{RecA}^{-} \mathrm{Sup}^{-} / \mathrm{pKN} 165$ host. The presence of the plasmid is necessary due to the poor suppression of the RecA- $\mathrm{Sup}^{-}$strain. Of the 50 mutants, eight were stringent, their e.o.p. being reduced by a factor of $10^{4}$ to $10^{5}$ in the absence of the plasmid (see results for Mucts ${ }_{62}$ SEEam8 Apl in Table 2), and the others were leaky, with an e.o.p. close to 1 . The method itself should not favour the selection of leaky mutants; the results obtained are probably due to the 'semi-essential' character of some of the genes in this region (Waggoner et al., 1981; Goosen et al., 1982). The eight stringent amber mutants (of which at least five must be independent) were shown to be in a single complementation group. Complementation tests between the leaky and stringent mutants are difficult to perform and it is not known whether these leaky mutants fall into other complementation groups.

One of the stringent amber mutants, Mucts ${ }_{62}$ SEEam8 Apl, was tested in more detail (Table 2). This mutant had a latent period of $60 \mathrm{~min}$ and a burst size of about 200 in the host $\mathrm{Sup}^{+} / \mathrm{pKN} 165$, and made normal plaques on this strain. Its efficiency of plating on the supD, supE, supF and supP strains was the same as that on the $\mathrm{Sup}^{+} / \mathrm{pKN} 165$ host, although on all these Sup- strains the plaques were smaller. On the $\sup C, \sup G$ and $\sup U$ strains the burst size was less than 1, as it was on the plasmid-free Sup ${ }^{+}$strain. Among the Sup ${ }^{-}$set of strains the largest plaques were found on the supF host, on which the burst size in lytic infection was reduced to about 25 . Under conditions where Mucts ${ }_{62} \mathrm{Apl}$ gave a lysogenization frequency of $10^{-1}$, the lysogenization frequency with $\mathrm{Mu} c \mathrm{ss}_{62}$ SEEam8 Apl was only $10^{-4}$ (tested on strains C600, RS 54, U709 and U706). Interestingly, this frequency was unaffected by whether the host strain was Sup ${ }^{-}$or $\mathrm{Sup}^{+}$(for technical reasons the lysogeny experiments could not be performed on strains carrying plasmid pKN165). 
As the only type of conditional lethal mutation that has been described previously in this region of the $\mathrm{Mu}$ genome is located in the lig gene, we did complementation tests between Mucts ${ }_{62}$ SEEam8 Apl and the mutant Muligts2 which lies within the lig gene. No complementation was observed in these tests, although normal complementation was found between am 8 and phage having an amber mutation in gene $C$. Work is in progress to confirm that the am8 mutation is in fact in the lig gene.

We are most grateful to N. Symonds for critical reading of the manuscript and to N. Rizzo for skilful technical assistance.

This work was supported by a grant of the Progetto Finalizzato Ingegneria Genetica del CNR, Italy.

\section{REFERENCES}

Bolivar, F., Rodriguez, R. L., Greene, P. J. Betlach, M. C., Heyneker, H. L., Boyer, H. W., Crosa, J. H. \& Falkow, S. (1977). Construction and characterization of new cloning vehicles. II. A multipurpose cloning system. Gene 2, 95-113.

Goosen, T., Giphart-Gassler, M. \& van de Putte, P. (1982). Bacteriophage Mu DNA replication is stimulated by non-essential early functions. Molecular and General Genetics 186, 135-139.

LEACH, D. \& SYMONDS, N. (1979). The isolation and characterization of a plaque forming derivative of bacteriophage $\mathrm{Mu}$ carrying a fragment of $\operatorname{Tn} 3$ conferring ampicillin resistance. Molecular and General Genetics 172, 179-195.

Paolozzi, L., Ghelardini, P., Liebart, J. C.. CapozZONI, A.\& MARCHELLI, C. (1980). Two classes of Mu lig mutants: the thermosensitives for integration and replication and the hyperproducers for ligase. Nucleic Acids Research 8, 5859-5874.

Schumann, W., Bade, E. G., Forgie, R. A. \& Howe, M. M. (1980). Cloning of DNA fragments of the right end of phage Mu and location of the HindIII, $S a l I, P s t I$ and BamHI restriction sites on the genetic map of Mu. Virology 104, 418-425.

Toussaint, A. \& Resibois, A. (1983). Phage Mu: transposition as a life style. In Mobile Genetic Elements, pp. 105-158. Edited by J. A. Shapiro. New York: Academic Press.

Waggoner, B. Pato, M., Toussaint, A. \& Faelen, M. (1981). Replication of mini-Mu prophage DNA. Virology 113, 378-387. 